\title{
Effects of Shoulder Geometry on Microstructures and Mechanical Properties of Probeless Friction Stir Spot Welded Aluminum 7075-T651 Sheets
}

\author{
Xingrong Chu ${ }^{1}$, Meng Yin ${ }^{1}$, Jun Gao ${ }^{1}$, Xiaowei Wang ${ }^{2, *}$ and Yangang Wang ${ }^{1}$ \\ 1 Associated Engineering Research Center of Mechanics and Mechatronic Equipment, Shandong University, \\ Weihai 264209, China; xrchu@sdu.edu.cn (X.C.); 201816484@mail.sdu.edu.cn (M.Y.); shdgj@sdu.edu.cn (J.G.); \\ wangyg@sdu.edu.cn (Y.W.) \\ 2 Shenzhen Zhenhua Microelectronics CO., LTD, Shenzhen 518000, China \\ * Correspondence: fly223@msn.com; Tel./Fax: +86-75526520788
}

Received: 3 November 2020; Accepted: 26 November 2020; Published: 30 November 2020

\begin{abstract}
In this work, three types of probeless tools (archimedes, involute, and concave tools) were designed. A 7075-T651 sheet of $1.0 \mathrm{~mm}$ thickness was welded using the designed probeless tools. It was found that the stir zone and hook defect varied a lot for different joints. Plunge depth was the dominant process parameter for joint property. The joint's maximum failure load (5.73 kN) was obtained with the concave tool when the target plunge depth was $0.55 \mathrm{~mm}$. Two typical joint fracture modes (shear fracture and plug fracture) were found using three designed tools with different plunge depths, rotation speeds, and dwell times. Shoulder geometry presented little influence on heat generation. Compared with involute grooves, archimedes grooves showed to be more effective on the material flow. The properties of the joints with the archimedes tool were more sensitive to welding parameters. Compared with the flat tool, the concave tool decreased the escape of plasticized material, improved the forge force, and optimized the metallurgical bond at the interface.
\end{abstract}

Keywords: probeless friction stir spot welding; tool geometry; processing parameters; microstructure; tensile-shear strength

\section{Introduction}

High-strength aluminum alloys are increasingly applied in the transportation and aerospace industries for their high specific strength character. The developments of spot joining techniques for aluminum alloys have thus grown in importance. However, conventional fusion welding technologies have shown considerable defects in welding operations of aluminum alloys [1-4]. Therefore, a solid-state bonding method, called friction stir spot welding (FSSW), has emerged as a new technique for welding aluminum alloys [5,6]. FSSW is a variant of friction stir welding (FSW), which is particularly suitable for lap joining of lightweight alloy sheets [7]. This process involves the plunge, dwell, and retract stages [8]. Liu et al. [9] emphasized that a keyhole that seriously deteriorates joint performance is left at the center of the joints after the processing. Several variants of FSSW have been applied for eliminating the keyhole defect, such as refill friction stir spot welding (RFSSW) and probeless friction stir spot welding (P-FSSW). Boldsaikhan et al. [10] pointed out that RFSSW is a derivative of FSSW, which does not leave a keyhole in the specimen. Uematsu et al. [11] compared the specimens of FSSW with a keyhole and a refilled one, and confirmed that the failure load is enhanced by refilling the probe hole. On the other hand, Li et al. [12] noted that the equipment for RFSSW is so complex that it is difficult to implement this technology in a wide application.

Subsequently, a greatly simplified welding technique named P-FSSW was proposed by Bakavos [13]. In their studies, optimum joints were produced using a short probe or a probeless 
tool. Bakavos et al. [14] confirmed that the material flow pattern during the welding was severely influenced by the characteristic of the tool surface. Tozaki et al. [15] used a scroll tool for the FSSW process, and high joint performance was obtained. This research also confirmed that the scroll grooves on the shoulder surface played an important role in material interactions, and plunge depth was the dominant processing parameter.

Although P-FSSW could decrease the disadvantages of a keyhole, there are still some barriers to the widespread implementation in the manufacturing industry, including hook defect and the capability limitation of welding thick plates [16]. Innovative methods, changing of welding parameters, and optimization of tool geometries are mainly used to improve the joints' properties. Li et al. [17] proposed FSSW plus subsequent friction stir welding (FSSW-FSW) to eliminate hook defect. Chiou et al. [18] proposed a probeless embedded tool to increase the friction coefficient and enhance heat generation during the welding process. Li et al. [12] employed an involute grooves tool for P-FSSW and investigated the effects of processing parameters on joint mechanical properties, microstructure, and morphology evolution. Liu et al. [19] found that the failure strength and surface quality of the joints welded by a six-groove tool were significantly improved. This study also suggested that grooves should not be too large or too far from the center of the shoulder. $\mathrm{Xu}$ et al. [20] found that the tool with a concave shape could assist the stirring of the material and accumulation and improve failure strength. So far, many research studies have been done to illustrate the effects of welding conditions on joint properties. However, studies about material interactions in joints welded with different tools are not sufficient. Further investigation is necessary to understand the mechanism of shoulder geometries during the P-FSSW process.

In this study, three types of new probeless tools were designed for welding, which were two flat tools with archimedes grooves and involute grooves and one concave tool with involute grooves. By using these tools, the P-FSSW processes were conducted on sheets of 7075-T651 alloy. The heat generation and material flow were experimentally studied. Subsequently, the microstructures and mechanical properties (failure strength, hardness) were evaluated. Based on the experimental results, the influences and mechanisms of shoulder geometry were discussed and revealed.

\section{Experiment}

The material welded in the research was a 7075-T651 aluminum alloy sheet with a thickness of $1 \mathrm{~mm}$. The failure strength and elongation were $572 \mathrm{MPa}$ and $11 \%$. The material chemical compositions are listed in Table 1.

Table 1. Chemical compositions (wt $\%$ ) of the used 7075-T651 alloy.

\begin{tabular}{cccccccccc}
\hline Alloy & Zn & Mg & Cu & Fe & Cr & Mn & Si & Ti & Al \\
\hline $7075-T 651$ & 5.7 & 2.6 & 1.6 & 0.33 & 0.24 & 0.1 & 0.05 & 0.03 & Bal. \\
\hline
\end{tabular}

Three probeless tools employed for lap welding in this experiment are presented in Figure 1. These tools were manufactured with $\mathrm{H} 13$ tool steel, and the shoulder diameter was $12 \mathrm{~mm}$. Figure 1a shows a flat tool with archimedes grooves on the shoulder, named archimedes tool. Figure $1 \mathrm{~b}$ shows an involute tool with a flat shoulder and involute grooves. Figure 1c presents a concave tool with involute grooves on the shoulder. All of the grooves have a diameter of $1 \mathrm{~mm}$, and the distance between the center of the shoulder and the end of the grooves is $1.4 \mathrm{~mm}$.

The experiments were conducted with a milling machine (BYJC Inc., Beijing, China), and the P-FSSW process was operated in the displacement control. A conventional steel anvil was used for welding. Acetone was used to clean the sheets before the welding processing. The influences of rotation speed, target plunge depth, and dwell time were investigated. The parameters of the P-FSSW process are shown in Table 2. The downward force was measured with a dynamometer system (Excon Technology Inc., Hangzhou, China). Temperature and material flow were also studied experimentally. As schematized in Figure 2, a K-type thermocouple was put into a blind hole $(8 \mathrm{~mm}$ 
from the center) to record the temperature. Tungsten powders (diameter of $0.05 \mathrm{~mm}$ ) were used to mark the flow track of the plasticized material. Four blind holes filled with tungsten powders were located at $1.4 \mathrm{~mm}$ from the center of the joints, so these marking powders could spread efficiently with the plasticized material flowing from the grooves.

(a)

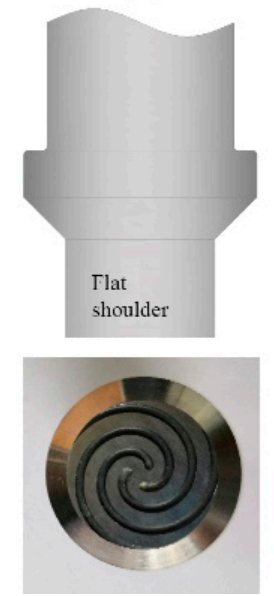

(b)

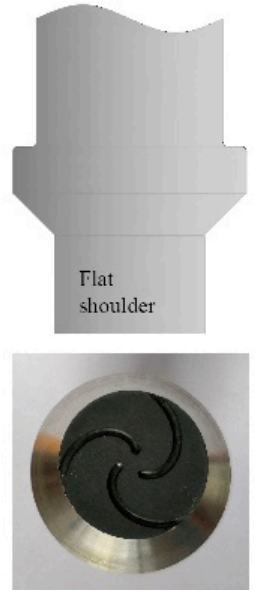

(c)

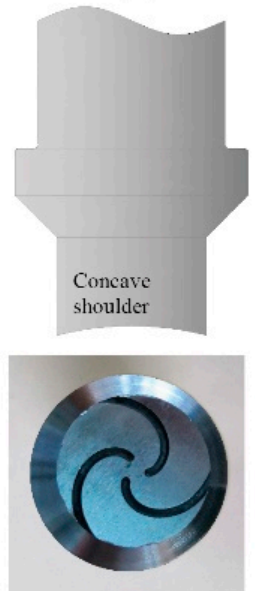

Figure 1. Configuration of probeless tools: (a) archimedes tool, (b) involute tool, and (c) concave tool.

Table 2. Parameters for P-FSSW.

\begin{tabular}{|c|c|}
\hline Rotation Speed (rpm) & $600,850,1100,1350,1600$ \\
\hline Plunge depth (mm) & $0.2,0.25,0.3,0.35,0.4,0.45,0.5$ \\
\hline Dwell time (s) & $7,9,11,13$ \\
\hline Plunge rate $(\mathrm{mm} / \mathrm{min})$ & 20 \\
\hline
\end{tabular}

Metallographs were obtained with optical microscopy (OM, KEYENCE (CHINA) CO., LTD, Shanghai, China). The specimens for observation were sectioned through the center of the joints, and then grounded, polished, and etched by Keller's reagent (2 mL HF, $3 \mathrm{~mL} \mathrm{HCl,} 5 \mathrm{~mL} \mathrm{HNO}, 190 \mathrm{~mL}$ $\mathrm{H}_{2} \mathrm{O}$ ). Vickers microhardness in the cross section of the joint was measured at a load of $200 \mathrm{~g}$ for $10 \mathrm{~s}$ with a step size of $0.5 \mathrm{~mm}$. In addition, a scanning electron microscope (SEM, FEI Nova NanoSEM 450, Oxford Instruments, Oxford, UK) and an energy dispersive X-ray spectrometer (EDS, OXFORD X-MaxN50, Oxford Instruments, Oxford, UK) were used to study the material flow.

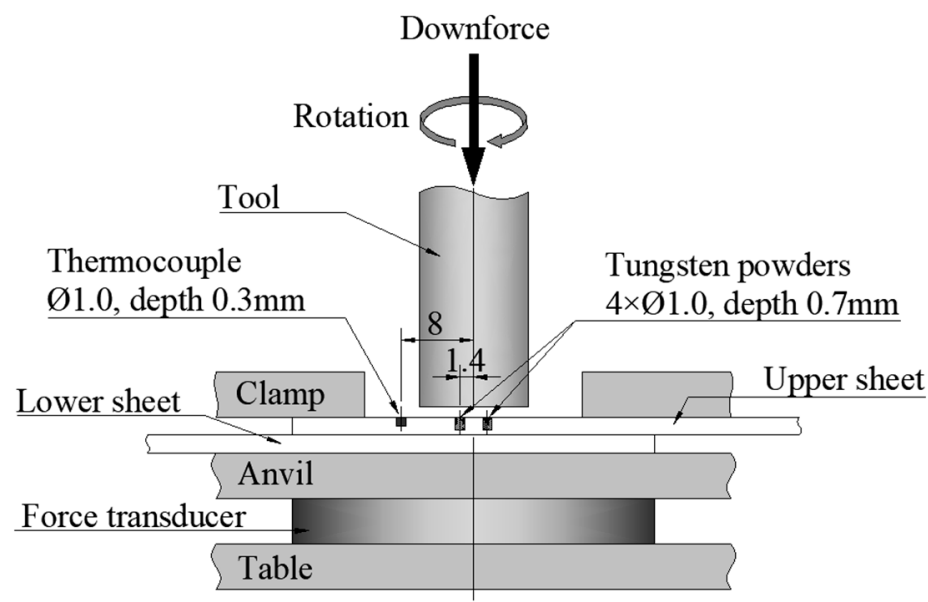

Figure 2. Schematic of the P-FSSW process and position illustration of the blind holes. 
Tensile-shear tests were conducted using the MTS E45.105 tester (MTS Industrial Systems (China) CO., LTD, Shenzhen, China) with a speed of $2 \mathrm{~mm} / \mathrm{min}$ to test the joint mechanical performance. The dimensions of the tensile-shear sample are shown in Figure 3. The failure strength for each condition was obtained according to the mean value of three tests. Subsequently, the fracture surfaces were analyzed with the scanning electron microscope (SEM, FEI Nova NanoSEM 450).

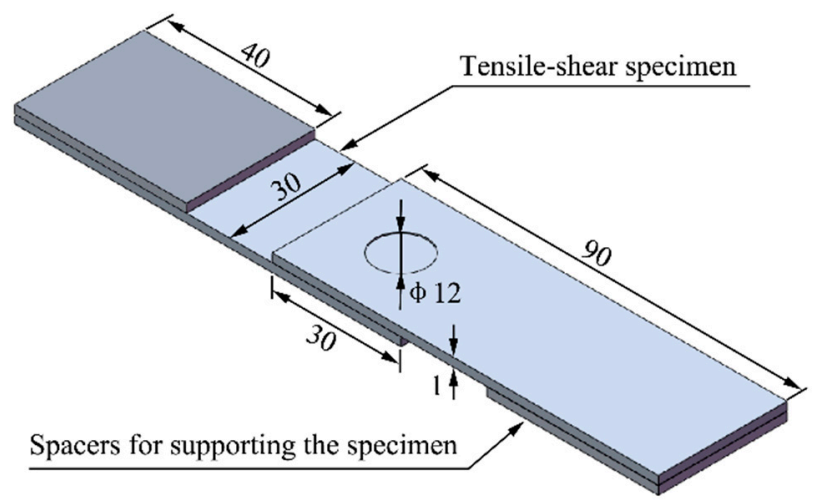

Figure 3. Configuration and size of the tensile-shear specimen (in $\mathrm{mm}$ ).

\section{Results and Discussions}

\subsection{Temperature during Processing}

To investigate heat generation during P-FSSW, the rotational speed (1100 rpm), dwell time (9 s), and plunge rate $(20 \mathrm{~mm} / \mathrm{min})$ were set constant for the three tools. It is worth noting that under the displacement control, the downward force was proportional to the plunge depth, as shown in Figure 4a. Therefore, it was feasible to obtain a similar downward force (the maximum downward force was $11 \pm 0.2 \mathrm{kN}$ ) by setting a plunge depth during the P-FSSW process. The temperature variations during the processing are presented in Figure $4 \mathrm{~b}$. It was found that the peak temperature of the concave tool came later than the others. This phenomenon is attributed to incomplete tool-workpiece contact during the plunge stage, which was caused by the concave shoulder shape. The peak values and the temperature curves were found to be very close. This indicates that the features of the shoulders presented little effect on heat generation.
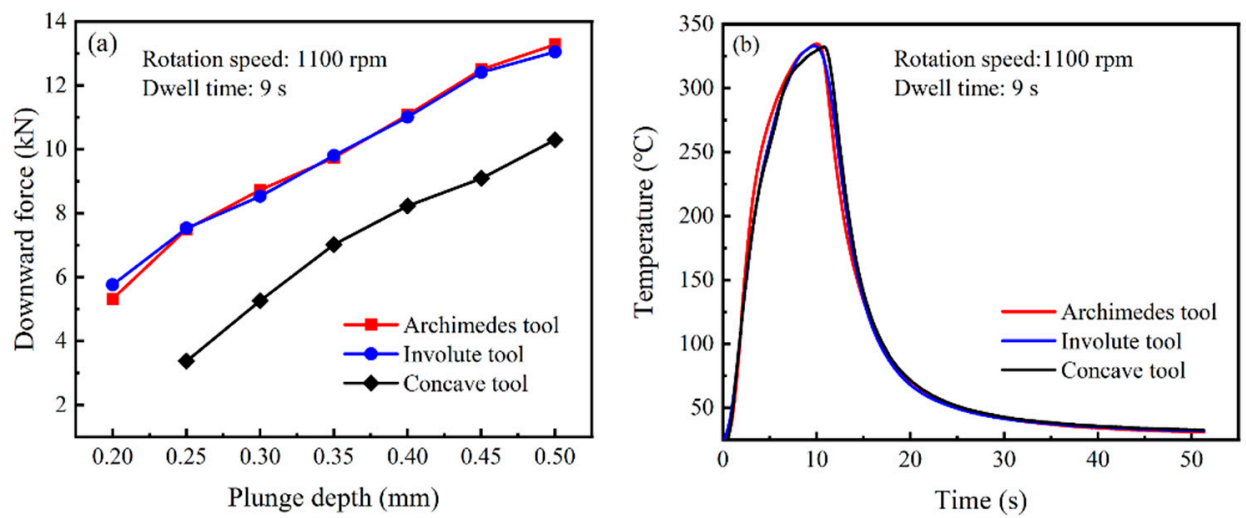

Figure 4. (a) Relationship of plunge depth with downward force; (b) temperature variations during the processing.

\subsection{Material Flow}

To better understand the formation of a joint during P-FSSW, the material flow was investigated by controlling the downward force at a similar value. Figure $5 \mathrm{a}-\mathrm{c}$ reveals the distributions of the marking 
material (tungsten powders) in three typical joints welded at a rotation speed of $1100 \mathrm{rpm}$ and dwell time of $9 \mathrm{~s}$. The rectangles with dotted red lines present the initial positions of the tungsten powders. Figure 5d,e is a SEM image and EDS spectra obtained from region A of Figure 5a. The spectra proved that the dark lines in these pictures consist of tungsten powders. It can be seen that the tungsten powders dispersed along the boundary of the stir zone, which reveals the track of the materials, and indicates the causal link between material flow and the formation of a microstructure. Moreover, the powders in the joint welded by the archimedes tool presented a uniform distribution. On the other hand, in the joints produced by the other two tools, the powders were more concentrated. It can be concluded that the archimedes grooves are more effective in promoting material flow.

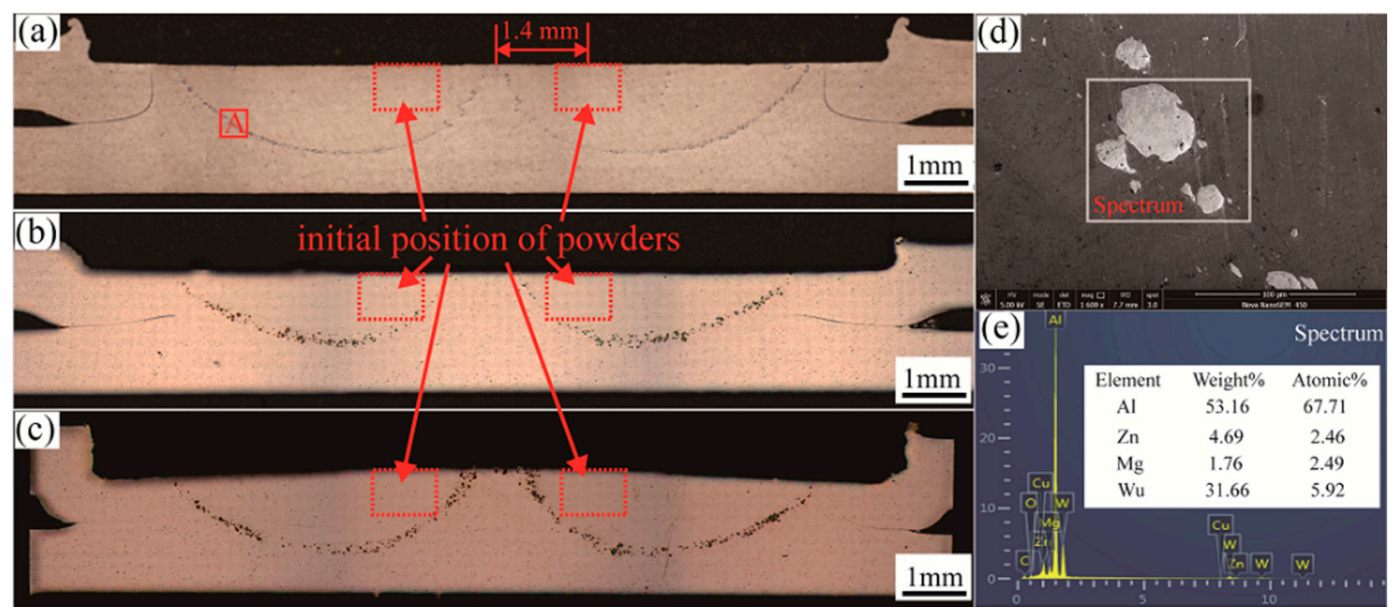

Figure 5. Distribution of tungsten powders in the cross sections of the joints produced by (a) the archimedes tool, (b) involute tool, (c) and concave tool and where (d) SEM image and (e) EDS spectra were obtained from region $\mathrm{A}$.

As Tozaki et al. [15] and Li et al. [12] presented, the friction heat softened the material beneath the shoulder. Driven by the friction force, the plasticized material would rotate and move radially toward the center of the shoulder. Subsequently, the material gathered at the center and then moved downward under the effect of the shoulder. Research studies carried out by Liu et al. [19] and Yang et al. [21] proved that the grooves greatly promoted the material flow. The plasticized materials flowed into the groove continuously due to the drive of the rotating tool, and then moved toward the end of the groove under the constraint of the groove wall. With the accumulation of plasticized materials, a relatively higher pressure was formed, and then the softened material was pushed downward. The base material far away from the heat source could not be sufficiently softened due to the existence of temperature gradients, and a restrictive space was built. Under the effects of the shoulder, grooves, and base materials, the plasticized material flowed circularly, as schematized in Figure 6.

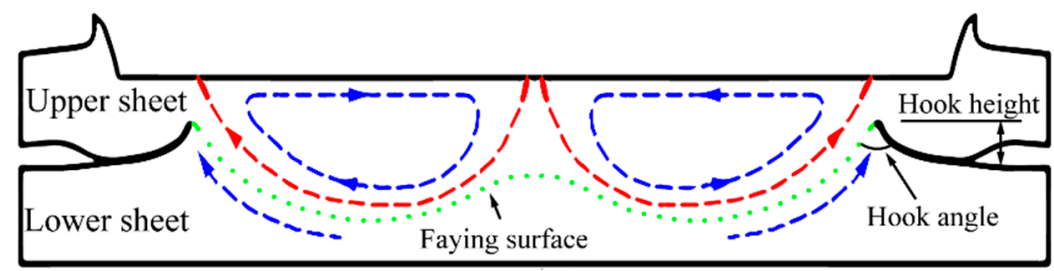

Figure 6. Schematic illustrations of the material flow during P-FSSW with a flat tool.

\subsection{Microstructure}

Typical cross sections of P-FSSW joints are shown in Figure 7. All of these joints were welded at a rotational speed of $1100 \mathrm{rpm}$ and dwell time of $9 \mathrm{~s}$. To obtain a similar downward force, the joints of 
the archimedes tool (Figure 7a) and involute tool (Figure $7 \mathrm{~b}$ ) were welded at a plunge depth of $0.3 \mathrm{~mm}$, and the joint of the concave tool (Figure 7c) was welded at a plunge depth of $0.4 \mathrm{~mm}$. A typical "basin shape" could be found from all of these joints. Figure $7 \mathrm{~d}$,f presents an enlarged drawing of regions A, B, and C in Figure 7c. These three distinct regions are defined as the stir zone (SZ), the thermal mechanically affected zone (TMAZ), and the heat-affected zone (HAZ). The SZ featured fine equiaxed grains. The very small grain structures were ascribed to the dynamic recrystallization caused by severe plastic deformation and high temperature. The TMAZ adjacent to the SZ was characterized by elongated, deformed, and bended grains, which were formed by thermal-mechanical deformation and partial recrystallization [22]. The HAZ went through the effects of the thermal cycle during the welding process and exhibited coarse grains [23].

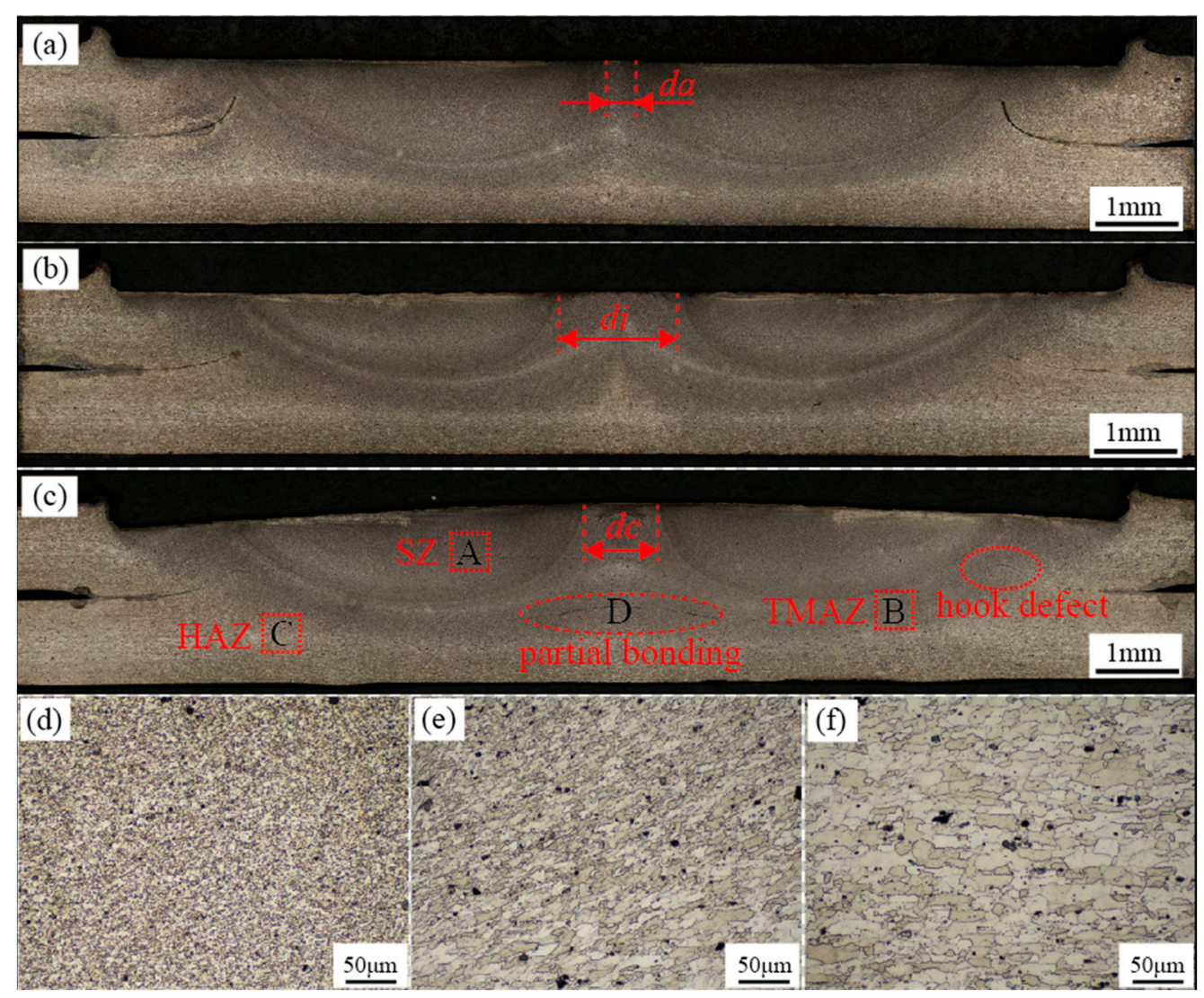

Figure 7. Microstructures of 7075-T651 aluminum alloy joints P-FSSWed with the (a) archimedes tool, (b) involute tool, (c) concave tool in regions (d) A, (e) B, and (f) C in Figure 7c, respectively.

It was easy to find that the boundary profile of the SZ was similar to the distribution of the marking powders shown in Figure 5, which indicates the relationship between material flow and the formation of SZ. In the stir zone, the material flowed and underwent severe thermal-mechanical interactions. The material adjacent to the SZ was heated, deformed, and recrystallized with the collisions of the heat material in the SZ, which enlarged the SZ continuously [24]. The more intense the heat material flowed, the larger the SZ was. Furthermore, the microstructures, such as the SZ and hook defects, of different joints varied a lot. As presented in Figure $7 \mathrm{a}-\mathrm{c}$, all the SZs were divided into two symmetrical sections, and the distances between the two separate parts were named $d_{a}, d_{i}$, and $d_{c}\left(d_{a}<d_{c}<d_{i}\right)$. For the archimedes grooves, this greatly facilitated the flow of the materials, which formed the largest $\mathrm{SZ}$ and the smallest $d_{a}$. For the flat shoulder with involute grooves, this was less dominant to the material flow, which caused the smallest SZ and the largest $d_{i}$. Although with same involute grooves, the concave tool reduced the material outflow and improved the pressure and thermal conditions, which developed the SZ and narrowed $d_{c}$. It should be noted that partial bonding appeared in region 
D (Figure 7c), suggesting insufficient local compress effect. It may be affected by the concave shoulder, which changed the direction of the material flow in the joint center and weakened the local interactions between the SZ and TMAZ.

The characteristics of the hook defects in the different joints varied a lot. The hook defect was a partial metallurgical bond, which severely reduced the joints' strength [25]. The plasticized materials of the lower sheet flew outward and upward to the upper sheet due to the push of the downward material at the center. Owing to the effects of this metallic material flow, the interface bended upward, and the hook defect with an inverted "V" shape was formed. This study used hook height and hook angle as the measurements of hook defect. As the schematic in Figure 6 shows, the hook height is described as the distance from the original interface to the top of the hook, and the hook angle is the angle of the " $\mathrm{V}$ " shape $[23,26]$. The surface characteristics of the shoulders and the welding parameters were dominant to the hook defect. As illustrated in Figure 8, for the archimedes tool, the hook height increased rapidly with the rise of the downward force, while the hook angle decreased quickly. However, both hook height and hook angle of the joints welded using involute and concave tools were slightly affected by the axial force.
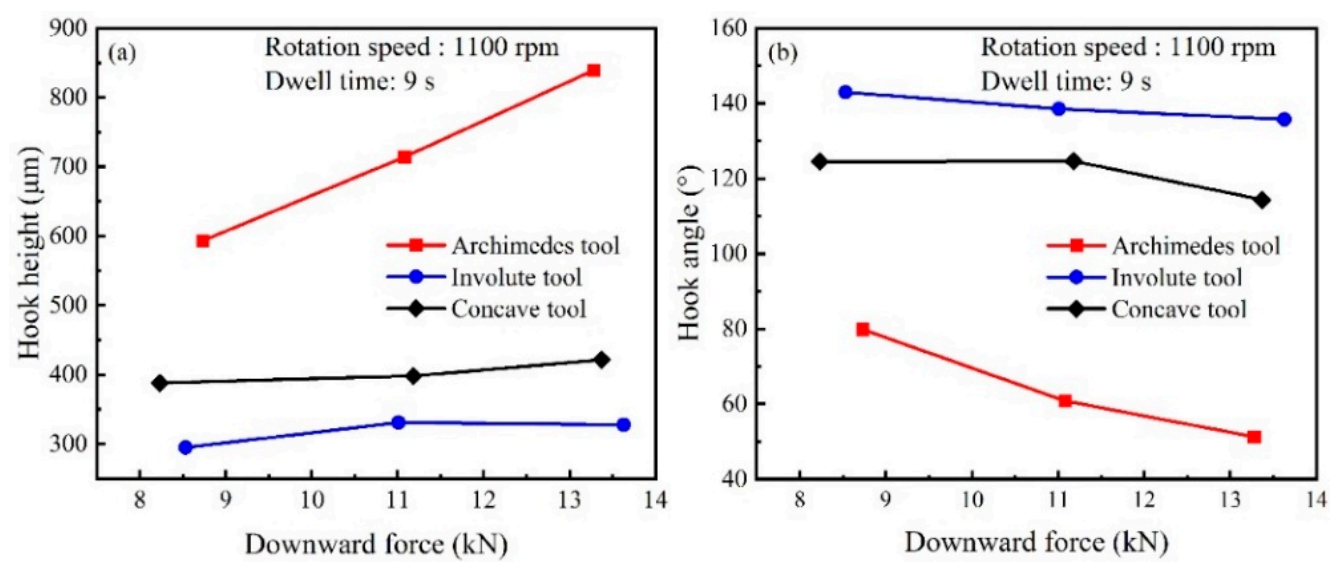

Figure 8. Effects of the downward force on (a) hook height and (b) hook angle.

\subsection{Mechanical Properties}

\subsubsection{Tensile-Shear Testing and Fracture Mechanism}

Figure 9 presents the experimental failure strength of the welds with different tools and different welding parameters. It is clear that the failure load was greatly influenced by the plunge depth. Figure 9a shows the curves of the failure load with plunge depth. For the joints welded with the archimedes tool, the tensile-shear strength increased to maximum at a target plunge depth of $0.3 \mathrm{~mm}$, and then showed a great decline. For the joints welded using the involute tool and concave tool, the failure load increased steadily with the plunge depth. Figure $9 \mathrm{~b}$ presents the relationship between failure load and dwell time, and Figure $9 \mathrm{c}$ presents the influence of rotation speed on failure load. For the archimedes tool, the failure strength of the joints decreased with the rotation speed and dwell time. However, for the involute tool, both the dwell time and rotation speed showed slight influences on the lap shear strength. Moreover, for the tool with a concave shoulder, the dwell time and rotational speed presented considerable influences on the joints' strength.

In order to figure out the effects of the shoulder shapes clearly, the relationship between failure strength and downward force at a constant rotation speed (1100 rpm) and dwell time $(9 \mathrm{~s})$ is shown in Figure $9 \mathrm{~d}$. The strongest joints with a tensile-shear strength of $5.73 \mathrm{kN}$ was obtained with a concave tool at a downward force of $11.18 \mathrm{kN}$ (plunge depth of $0.55 \mathrm{~mm}$ ). Based on the results shown in Figure 9, the failure strength of the P-FSSWed joint with the archimedes tool was sensitive to welding 
parameters. In welding with a plunge depth smaller than $0.3 \mathrm{~mm}$ or rotational speed lower than $1100 \mathrm{rpm}$, the archimedes tool presented a better joint strength.
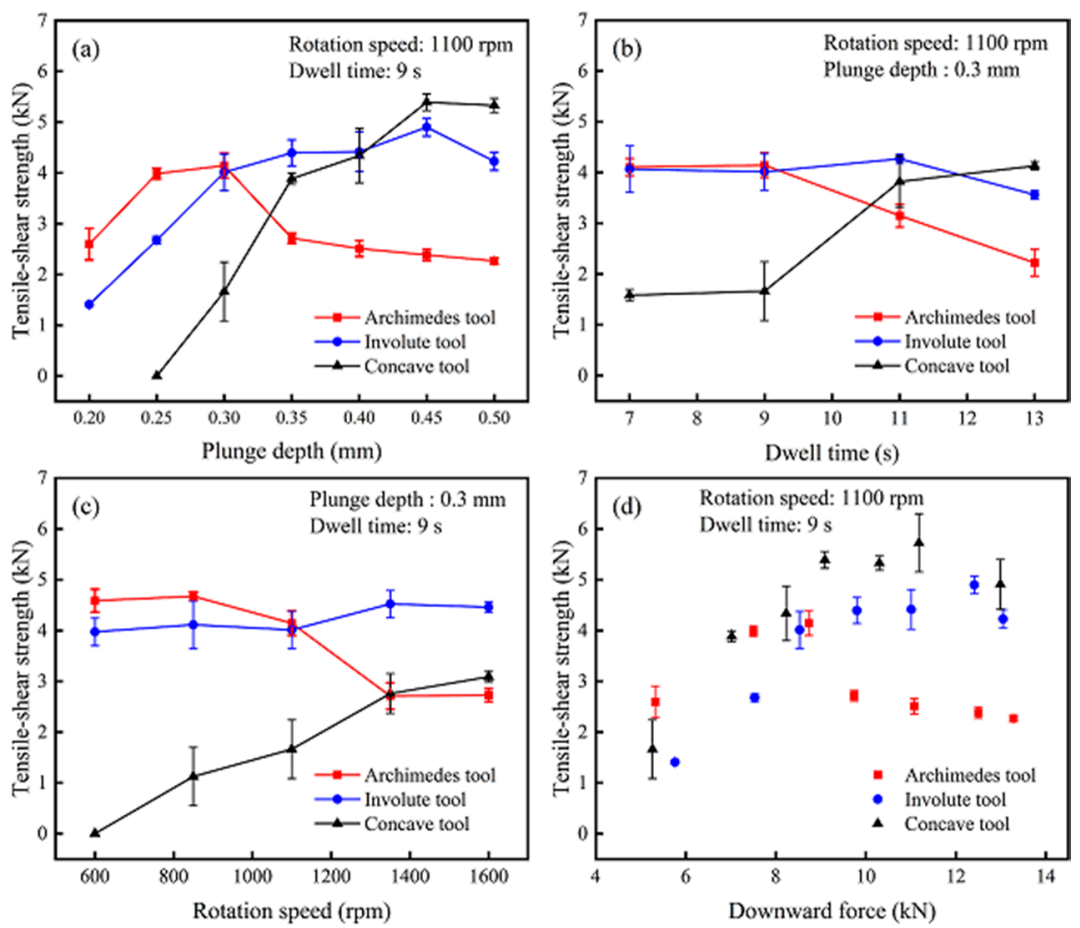

Figure 9. Evolution of tensile-shear strength with (a) plunge depth, (b) dwell time, (c) rotation speed, (d) downward force.

For the joints welded with different tools, two fracture modes (shear fracture and plug fracture) were found for lap shear testing, as shown in Figure 10. Figure 10a presents shear fracture mode in which two plates were sheared off along the interface of both plates. Figure $10 \mathrm{~b}$ presents plug fracture mode that was caused by the thickness reduction of the joints. The plug fracture occurred along the extension of the hook outside edge, and the SZ was completely left on the bottom sheet. Research studies have confirmed that plug fracture is detrimental to joint strength $[12,15,27]$. At the parameters of a rotation speed of $1100 \mathrm{rpm}$ and dwell time of $9 \mathrm{~s}$, for the archimedes tool, when the plunge depth was greater than $0.3 \mathrm{~mm}$, the joints were broken in the form of a plug fracture. The plug fracture led to the decrease of joint strength, as shown in Figure 9a. In the case of the involute tool, shear fracture was observed when the plunge depth was lower than $0.50 \mathrm{~mm}$. For the concave tool, the plug fracture of the joint was observed when the target plunge depth exceeded $0.55 \mathrm{~mm}$. Increase of plunge depth led to better interaction of the welded materials. For the concave tool, joint strength increased with aplunge depth of about $0.55 \mathrm{~mm}$.
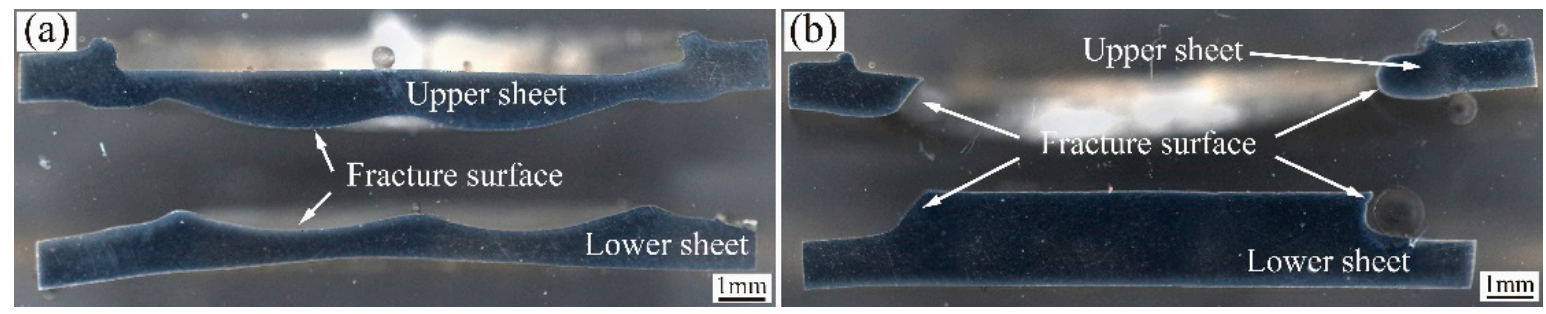

Figure 10. Macrostructures of cross sections for two typical fracture modes: (a) shear fracture and (b) plug fracture. 
Typical fractographs of the joints are shown in Table 3. The shear fracture surface of the joint welded by the archimedes tool presented a large number of elongated dimples and obvious tearing edges, indicating better bonding between the top and bottom sheets. Dense dimples and tearing edges could also be found on the shear fracture surface welded by the involute tool. For the joint welded by the concave tool, the center of the fracture surface presented large dimples and long tearing edges extending along the shear direction, indicating poor metallurgical bonding of the interface. Additionally, this fracture feature agreed well with the partial bonding at the D region shown in Figure 7c. This was mainly caused by the insufficient stirring effects at the joint center. In addition, the second-phase particles could be observed at the base of the dimples; these particles were considered the source of the dimples. The plug fracture surface in Table 3 was produced by the archimedes tool. This plug fracture surface was mainly composed of flat cleavage surfaces, indicating weak bonding at the outer edge of the hook.

Table 3. Fractographs of the different facture modes in the bottom sheets.

\begin{tabular}{|c|c|c|}
\hline $\begin{array}{c}\text { Fracture } \\
\text { Mode }\end{array}$ & Parameters & Fractograph \\
\hline $\begin{array}{l}\text { Shear } \\
\text { fracture }\end{array}$ & $\begin{array}{c}\text { Archimede, } \\
\text { RS = 1100, } \\
\text { DT =9, } \\
\text { PD }=0.3\end{array}$ & \\
\hline $\begin{array}{l}\text { Shear } \\
\text { fracture }\end{array}$ & $\begin{array}{c}\text { Involute, } \\
\text { RS = 1100, } \\
\text { DT =9, } \\
\text { PD = 0.4 }\end{array}$ & \\
\hline $\begin{array}{c}\text { Shear } \\
\text { fracture }\end{array}$ & $\begin{array}{c}\text { Concave, } \\
\text { RS = 1100, } \\
\text { DT =9, } \\
\text { PD = 0.4 }\end{array}$ & \\
\hline $\begin{array}{c}\text { Plug } \\
\text { fracture }\end{array}$ & $\begin{array}{c}\text { Archimedes, } \\
\text { RS = 1100, } \\
\text { DT =9, } \\
\text { PD }=0.4\end{array}$ & \\
\hline
\end{tabular}

RS—rotation speed (rpm), DT—dwell time (s), and PD—plunge depth (mm).

\subsubsection{Microhardness}

Figure 11 presents the Vickers microhardness profiles of the joints welded with different tools. The microhardness values were detected in the middle of the top sheets. These joints were welded at same rotation speed $(1100 \mathrm{rpm})$ and dwell time $(9 \mathrm{~s})$, and the maximums of the downward force were controlled at about $11 \mathrm{kN}$. The curves of the hardness distribution showed a symmetrical " $\mathrm{W}$ " shape, and the microhardness distribution indicated that the microstructure of the joint was inhomogeneous. A maximum hardness of $165 \mathrm{HV}$ was found in the Base metal (BM). The hardness value decreased to 
$120 \mathrm{HV}$ in the HAZ. The change of grain size and evolution of strengthening precipitates contributed to the differences of hardness in different regions $[22,28,29]$. The peak temperature in the HAZ (as shown in Figure 4) approached $340{ }^{\circ} \mathrm{C}$, which caused grain coarsening, complete dissolution of fine particles, and partial dissolution of larger precipitates. Then the further growth of larger particles appeared during the cooling stage [30]. The reduction of hardness in the HAZ was attributed to the comprehensive effects of grain coarsening and overaging [31,32]. The hardness in the SZ (140-150 HV) was lower than that of the BM and higher than that of the HAZ, which was caused by the comprehensive influence of grain refinement, precipitate dissolution during welding stage, and reprecipitation of $\eta$ particles $\left(\mathrm{MgZn}_{2}\right)$ during the cooling stage [33]. In addition, for the joints welded with three different tools, there was little microhardness difference in the HAZ. This was attributed to the similar temperature evolution of the three tools during the welding process, as shown in Figure 4.

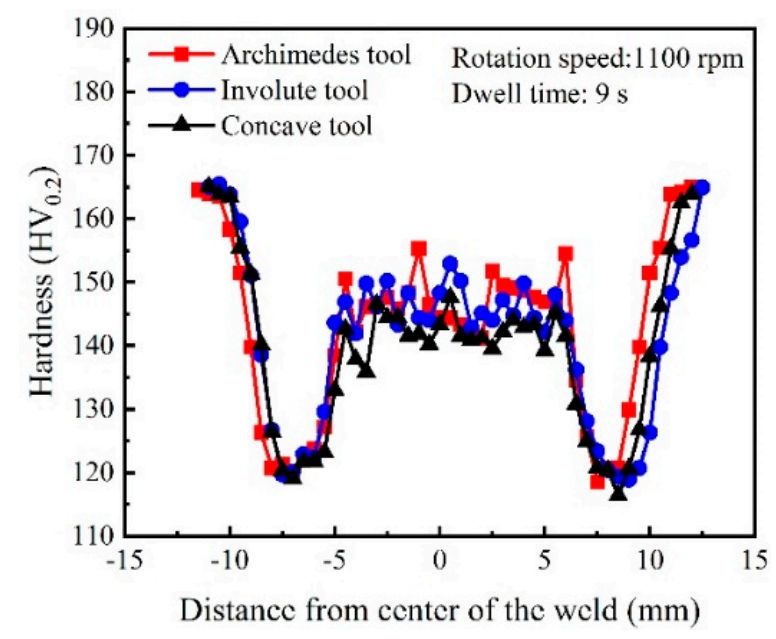

Figure 11. Microhardness measured at the cross sections of the P-FSSW joints.

\subsection{Shoulder Geometries' Influences on Microstructures and Properties}

Figure $9 \mathrm{~d}$ shows that the joint welded with the concave tool presented superior tensile-shear strength, while the performance of the joint welded using the archimedes tool showed a decline when the axial force was larger than $8.73 \mathrm{kN}$. The rapid development of the hook defect was the reason for the performance decline when the joint was welded by the archimedes tool. Research carried out by Li et al. [12] illustrated that the developments of hook height and hook angle were detrimental to the joints' properties. As shown in Figure 8, compared with the joints welded with the other tools, the joints welded by the archimedes tool presented larger hook height and smaller hook angle. With the increase of plunge depth, the hook height increased inevitably, thus seriously limiting the further enhancement of tensile-shear strength. Figure 5 reveals that the archimedes grooves presented the most significant promoting effects on the material flow This was the primary cause of the most serious hook defect produced by the archimedes tool.

Figure $9 \mathrm{~d}$ presents the advantage of the concave tool to produce high-strength joints. Inconsistent with this results, the concave tool caused larger hook height and smaller hook angle (shown in Figure 8), which tended to decrease the joints' strength. Besides, the concave shoulder presented few advantages over the flat shoulder in heat generation, as shown in Figure 4. For the FSSW process, it was accepted that the insufficient disruption of oxide film contributed to the formation of different bond characteristics. The presence of interfacial oxide diminished the strength of the FSSWed joints [34]. When the welded joint was subjected to external loading, crack would initially occur along the hook and then propagate following the oxide layer. Bakavos [13] classified the faying surface into kissing 
bond, partial metallurgical bond, and full metallurgical bond and proposed that the strongest joints are obtained with the greatest proportion of full metallurgical bond.

Figure 12 presents the cross sections and the interfacial bonding of the joints with different tools under the same rotation speed (1100 rpm), dwell time (9 s), and downward force (11 $\pm 0.2 \mathrm{kN})$. A considerable difference between the interfacial metallurgical bond was found at the hook region after etching. The unbonded region, kissing-bonded region, and partial metallurgical bonded region existed in sequence from the periphery of the joint to the inside of the hook. Figure 12a shows the joint welded by the concave tool; a typical kissing bond existed at the outside of the hook, as shown in Figure 12a1. Next to this region was the partial metallurgical bonded region (Figure 12a2), where intermittent voids and discontinuous oxide particles occurred. On the inside of the hook (Figure 12a3), the initial layered surface oxide was broken into small particles, and the partial bonding became less prominent. All of these characteristics indicated severe plastic deformation at the regions near the hook defect. Figure $12 \mathrm{~b}$ presents the joint welded with the involute tool. As shown in Figure 12b1, the unbonded region propagated till the top of the hook, and the interface at the top of the hook was a typical kissing bond (Figure 12b2). In addition, the original interface oxide still existed as long segments on the inside of the hook (Figure 12b3). The difference in interface characteristics between the two joints suggests the advantages of the concave tool in enhancing the mechanical effects in the area near the hook.

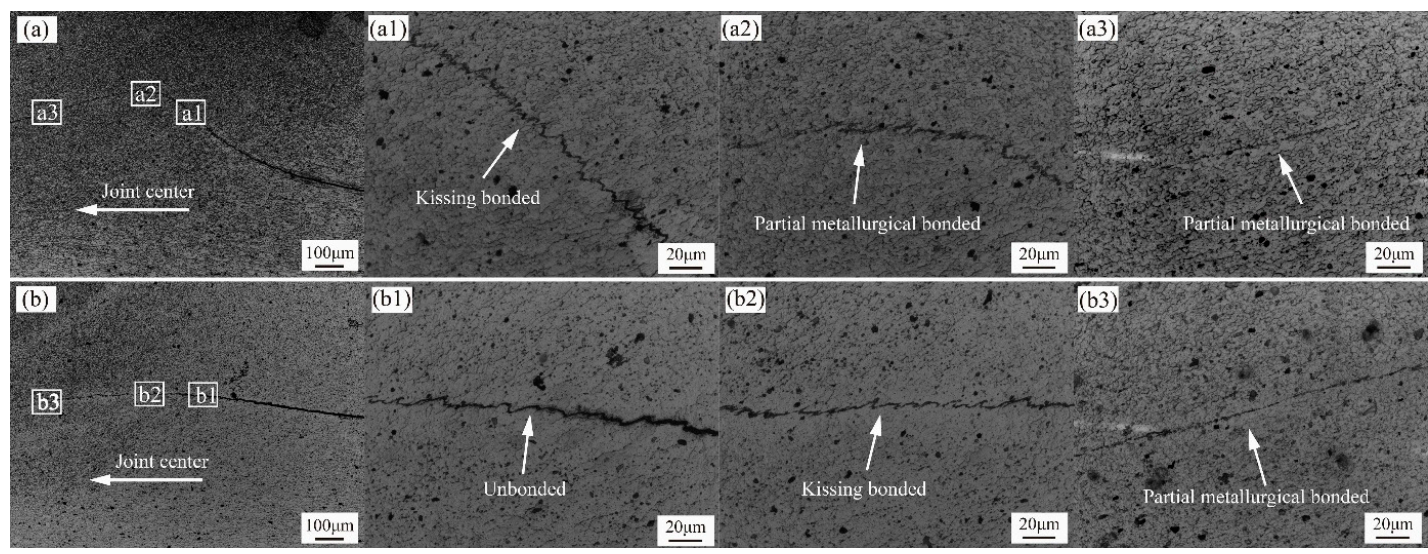

Figure 12. Optical micrographs of metallurgical bonding in the joints welded with the (a) concave tool and (b) involute tool. (a1-a3) were amplification of the interfacial metallurgical bond in Figure 12a. (b1-b3) were amplification of the interfacial metallurgical bond in Figure 12b.

The mechanisms of the shoulders on the material interaction during the welding process are shown in Figure 13. Compared with the flat shoulder, the concave shoulder can change the direction of the force on the outside of the hook. The hook height would increase, and the hook angle would decrease at the push of this force. Meanwhile, the concave design reduced the escape of the plasticized material and the formation of flash, thus enhancing the forging force on the periphery of the joint $[20,35]$. These advantages of the concave shoulder promoted the breaking and fragmentation of the initial oxidation film and improved the metallurgical bond at the interface. It was the reason why the joints welded with the concave tool presented the optimum tensile-shear strength. 
(a)

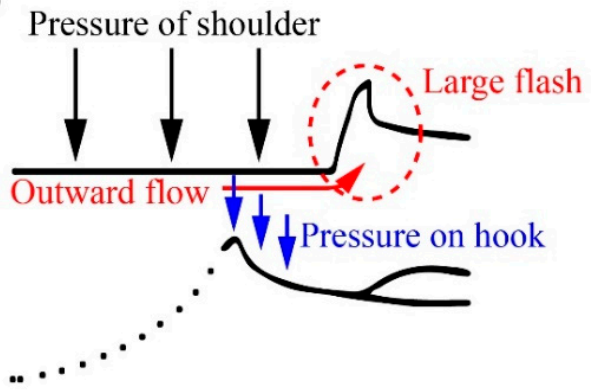

(b) Pressure of shoulder

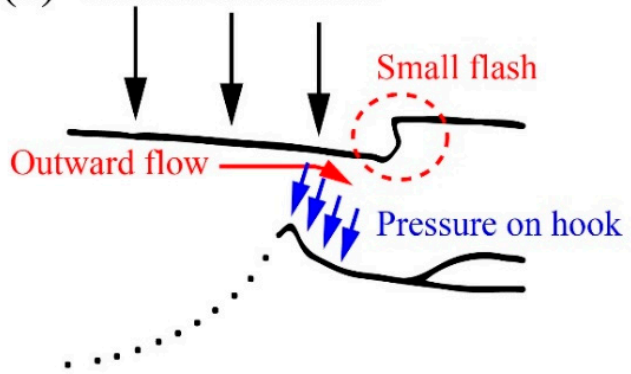

Figure 13. Schematic illustrations of the interaction in the P-FSSW process with the (a) flat tool and (b) concave tool.

\section{Conclusions}

In this work, P-FSSW was conducted on 7075-T651 aluminum alloy sheets of $1 \mathrm{~mm}$ thickness with the self-designed tools. The influences of the processing parameters and shoulder geometry on lap shear strength were investigated. Based on these works, several conclusions were drawn:

(1) The geometry characteristics of the shoulder surface presented little influence on heat generation during the P-FSSW process, while the shoulder features, especially the grooves, showed great effects on the material flow.

(2) The microstructure characteristics of the hook defects were significantly affected by the shoulder geometry and welding parameters. When welding with a plunge depth lower than $0.3 \mathrm{~mm}$ or a rotational speed smaller than $1100 \mathrm{rpm}$, the archimedes tool presented higher joint strength. With the increase of the axial force, the concave tool presented advantages in producing stronger joints. Moreover, the hook defect and correlated joint strength were more sensitive to the welding parameters with the archimedes tool.

(3) The plunge depth presented the most significant effect on tensile-shear strength, followed by rotation speed and dwell time. Moreover, the optimum strength was obtained at the parameters, which led to shear fracture.

(4) The concave tool was an ideal scheme for welding $1 \mathrm{~mm}$ sheets of 7075-T651 aluminum alloy, and a maximum fracture load of $5.73 \mathrm{kN}$ was achieved by the concave tool. The concave shoulder enhanced the forging force on the materials at the periphery of the joint and optimized the metallurgical bonding, thus increasing the tensile-shear strength.

Author Contributions: Writing, editing, study design, data analysis, X.C.; writing, data analysis, data interpretation, M.Y.; data analysis, editing, J.G.; study design, editing, data analysis, X.W.; experiment, data collection, Y.W. All authors have read and agreed to the published version of the manuscript.

Funding: The authors would like to acknowledge the financial support from the Natural Science Foundation of Shandong Province (no. ZR2019MEE008), National Natural Science Foundation of China (no. 5197532), and Major Innovation Project of Shandong Province (no. 2019TSLH0103).

Acknowledgments: This work is supported by the Physical-Chemical Materials Analytical and Testing Center of Shandong University at Weihai.

Conflicts of Interest: The authors declare no conflict of interest.

\section{References}

1. Çevik, B. Gas tungsten arc welding of 7075 aluminum alloy: Microstructure properties, impact strength, and weld defects. Mater. Res. Express 2018, 5, 066540. [CrossRef]

2. Shen, Z.; Ding, Y.; Chen, J.; Fu, L.; Liu, X.; Chen, H.; Guo, W.; Gerlich, A. Microstructure, static and fatigue properties of refill friction stir spot welded 7075-T6 aluminium alloy using a modified tool. Sci. Technol. Weld. Join. 2019, 24, 587-600. [CrossRef] 
3. Sadoun, A.; Wagih, A.; Fathy, A.; Essa, A. Effect of tool pin side area ratio on temperature distribution in friction stir welding. Results Phys. 2019, 15, 102814. [CrossRef]

4. Deng, L.; Li, S.; Ke, L.; Liu, J.; Kang, J. Microstructure and Fracture Behavior of Refill Friction Stir Spot Welded Joints of AA2024 Using a Novel Refill Technique. Metals 2019, 9, 286. [CrossRef]

5. Zhang, Z.; Yu, Y.; Zhao, H.; Wang, X. Interface Behavior and Impact Properties of Dissimilar Al/Steel Keyhole-Free FSSW Joints. Metals 2019, 9, 691. [CrossRef]

6. Reimann, M.; Goebel, J.; Dos Santos, J.F. Microstructure and mechanical properties of keyhole repair welds in AA 7075-T651 using refill friction stir spot welding. Mater. Des. 2017, 132, 283-294. [CrossRef]

7. Ibrahim, I.J.; Yapıc1, G.G. Application of a novel friction stir spot welding process on dissimilar aluminum joints. J. Manuf. Process. 2018, 35, 282-288. [CrossRef]

8. Padhy, G.; Wu, C.; Gao, S. Friction stir based welding and processing technologies-Processes, parameters, microstructures and applications: A review. J. Mater. Sci. Technol. 2018, 34, 1-38. [CrossRef]

9. Liu, J.; Song, Q.; Song, L.; Ji, S.; Li, M.; Jia, Z.; Yang, K. A Novel Friction Stir Spot Riveting of Al/Cu Dissimilar Materials. Acta Met. Sin. Engl. Lett. 2020, 1-10. [CrossRef]

10. Boldsaikhan, E.; Fukada, S.; Fujimoto, M.; Kamimuki, K.; Okada, H. Refill friction stir spot welding of surface-treated aerospace aluminum alloys with faying-surface sealant. J. Manuf. Process. 2019, 42, 113-120. [CrossRef]

11. Uematsu, Y.; Tokaji, K.; Tozaki, Y.; Kurita, T.; Murata, S. Effect of re-filling probe hole on tensile failure and fatigue behaviour of friction stir spot welded joints in Al-Mg-Si alloy. Int. J. Fatigue 2008, 30, 1956-1966. [CrossRef]

12. Li, W.; Chu, Q.; Yang, X.; Shen, J.; Vairis, A.; Wang, W. Microstructure and morphology evolution of probeless friction stir spot welded joints of aluminum alloy. J. Mater. Process. Technol. 2018, 252, 69-80. [CrossRef]

13. Bakavos, D.; Prangnell, P.B. Effect of reduced or zero pin length and anvil insulation on friction stir spot welding thin gauge 6111 automotive sheet. Sci. Technol. Weld. Join. 2009, 14, 443-456. [CrossRef]

14. Bakavos, D.; Chen, Y.; Babout, L.; Prangnell, P. Material Interactions in a Novel Pinless Tool Approach to Friction Stir Spot Welding Thin Aluminum Sheet. Met. Mater. Trans. A 2010, 42, 1266-1282. [CrossRef]

15. Tozaki, Y.; Uematsu, Y.; Tokaji, K. A newly developed tool without probe for friction stir spot welding and its performance. J. Mater. Process. Technol. 2010, 210, 844-851. [CrossRef]

16. Chu, Q.; Li, W.; Yang, X.; Shen, J.; Vairis, A.; Feng, W.; Wang, W. Microstructure and mechanical optimization of probeless friction stir spot welded joint of an Al-Li alloy. J. Mater. Sci. Technol. 2018, 34, 1739-1746. [CrossRef]

17. Li, W.; Li, J.; Zhang, Z.; Gao, D.; Wang, W.; Dong, C. Improving mechanical properties of pinless friction stir spot welded joints by eliminating hook defect. Mater. Des. 2014, 62, 247-254. [CrossRef]

18. Chiou, Y.-C.; Liu, C.-T.; Lee, R.-T. A pinless embedded tool used in FSSW and FSW of aluminum alloy. J. Mater. Process. Technol. 2013, 213, 1818-1824. [CrossRef]

19. Liu, Z.; Cui, H.; Ji, S.; Xu, M.; Meng, X. Improving Joint Features and Mechanical Properties of Pinless Fiction Stir Welding of Alcald 2A12-T4 Aluminum Alloy. J. Mater. Sci. Technol. 2016, 32, 1372-1377. [CrossRef]

20. Xu, R.; Ni, D.; Yang, Q.; Liu, C.; Ma, Z. Pinless Friction Stir Spot Welding of Mg-3Al-1Zn Alloy with Zn Interlayer. J. Mater. Sci. Technol. 2016, 32, 76-88. [CrossRef]

21. Yang, X.; Feng, W.; Li, W.; Xu, Y.; Chu, Q.; Ma, T.; Wang, W. Numerical modelling and experimental investigation of thermal and material flow in probeless friction stir spot welding process of Al 2198-T8. Sci. Technol. Weld. Join. 2018, 23, 704-714. [CrossRef]

22. Xu, N.; Feng, R.-N.; Guo, W.-F.; Song, Q.-N.; Bao, Y.-F. Effect of Zener-Hollomon Parameter on Microstructure and Mechanical Properties of Copper Subjected to Friction Stir Welding. Acta Met. Sin. Engl. Lett. 2020, 33, 319-326. [CrossRef]

23. Cao, J.; Wang, M.; Kong, L.; Guo, L. Hook formation and mechanical properties of friction spot welding in alloy 6061-T6. J. Mater. Process. Technol. 2016, 230, 254-262. [CrossRef]

24. Liu, F.; Hovanski, Y.; Miles, M.P.; Sorensen, C.; Nelson, T. A review of friction stir welding of steels: Tool, material flow, microstructure, and properties. J. Mater. Sci. Technol. 2018, 34, 39-57. [CrossRef]

25. Badarinarayan, H.; Shi, Y.; Li, X.; Okamoto, K. Effect of tool geometry on hook formation and static strength of friction stir spot welded aluminum 5754-O sheets. Int. J. Mach. Tools Manuf. 2009, 49, 814-823. [CrossRef] 
26. Wang, T.; Sidhar, H.; Mishra, R.S.; Hovanski, Y.; Upadhyay, P.; Carlson, B. Effect of hook characteristics on the fracture behaviour of dissimilar friction stir welded aluminium alloy and mild steel sheets. Sci. Technol. Weld. Join. 2018, 24, 178-184. [CrossRef]

27. Ji, S.; Sun, X.; Ma, Z.; Gong, P.; Wen, Q. Friction stir diffusion welding realized by a novel tool with turbo-like pin. Mater. Sci. Eng. A 2020, 800, 140369. [CrossRef]

28. Chen, S.; Li, X.; Jiang, X.; Yuan, T.; Hu, Y. The effect of microstructure on the mechanical properties of friction stir welded 5A06 Al Alloy. Mater. Sci. Eng. A 2018, 735, 382-393. [CrossRef]

29. Sato, Y.S.; Urata, M.; Kokawa, H.; Ikeda, K. Hall-Petch relationship in friction stir welds of equal channel angular-pressed aluminium alloys. Mater. Sci. Eng. A 2003, 354, 298-305. [CrossRef]

30. Mahoney, M.W.; Rhodes, C.G.; Flintoff, J.G.; Bingel, W.H.; Spurling, R.A. Properties of friction-stir-welded 7075 T651 aluminum. Met. Mater. Trans. A 1998, 29, 1955-1964. [CrossRef]

31. Gemme, F.; Verreman, Y.; Dubourg, L.; Wanjara, P. Effect of welding parameters on microstructure and mechanical properties of AA7075-T6 friction stir welded joints. Fatigue Fract. Eng. Mater. Struct. 2011, 34, 877-886. [CrossRef]

32. Shen, Z.; Yang, X.; Zhang, Z.; Cui, L.; Li, T. Microstructure and failure mechanisms of refill friction stir spot welded 7075-T6 aluminum alloy joints. Mater. Des. 2013, 44, 476-486. [CrossRef]

33. Gerlich, A.; Avramovic-Cingara, G.; North, T.H. Stir zone microstructure and strain rate during Al 7075-T6 friction stir spot welding. Met. Mater. Trans. A 2006, 37, 2773-2786. [CrossRef]

34. Chu, Q.; Yang, X.; Li, W.-Y.; Lu, T.; Zhang, Y.; Vairis, A.; Wang, W. Impact of surface state in probeless friction stir spot welding of an Al-Li alloy. Sci. Technol. Weld. Join. 2019, 24, 200-208. [CrossRef]

35. Badarinarayan, H.; Yang, Q.; Zhu, S. Effect of tool geometry on static strength of friction stir spot-welded aluminum alloy. Int. J. Mach. Tools Manuf. 2009, 49, 142-148. [CrossRef]

Publisher's Note: MDPI stays neutral with regard to jurisdictional claims in published maps and institutional affiliations. 